\title{
Ciência, tecnologia e sociedade e formação do engenheiro: análise da legislação vigente
}

Science, technology and society and engineering curriculum: analysis of current legislation

Tatiana C. Menestrina

Walter Antônio Bazzo

\begin{abstract}
Resumo
São apresentados, neste artigo, inicialmente, determinados enfoques teóricos com o objetivo de evidenciar algumas concepções acerca dos paradigmas educacionais, ensino de engenharia, epistemologia da construção do conhecimento em educação e as perspectivas em termos de Ciência, Tecnologia e Sociedade-CTS. Como segundo aspecto analisa-se, a "Legislação nacional: um recorte para os cursos de Engenharia" apresentando a LDB (Leis de Diretrizes e Bases da Educação) e as Diretrizes Curriculares que norteiam os cursos de Engenharia no Brasil e que demarcam as principais questões para a construção de Projetos Pedagógicos dos Cursos - PPPs. Realiza-se uma apreciação teórica e conceitual, pois se entende que só a partir dela é possível compreender o que é esperado do engenheiro em termos de habilidades e competências. "A Formação do Engenheiro numa perspectiva de CTS: uma realidade a ser estudada", aponta para questões relativas à Ciência, Tecnologia e Sociedade-CTS vinculados a ensino de engenharia. As concepções de CTS têm sido motivo de constantes estudos, entre os diversos segmentos sociais. A proposta deste artigo é, portanto, uma reflexão sobre a possibilidade da formação de engenheiros cidadãos que tenham a capacidade de valer-se dos conhecimentos acadêmicos em seu dia-a-dia, interatuando com a Sociedade na qual estão inseridos.
\end{abstract}

Palavras-chave: CTS, Ensino de Engenharia, Legislação Vigente

Abstract

The purpose of this work is to analyze the proposals of Science, Technology and Society - STS presented in the Law of Directives and Bases of 
Brazilian Education - LDB and the National Curriculum Directives for the Courses in Engineering. The theoretical foundation that supports this discussion is in respect to the teaching of Engineering and the conceptions regarding Science, Technology and Society - STS. From this, it is proposed to analyze the perspectives for the education of the professional engineer, observing the overall perspectives that refer to the pedagogic, socio-cultural and political aspects. In this article, the "National Legislation: an outline for Engineering courses" will be analyzed, presenting the LDB (Laws of Directives and Bases of Education) and the Curriculum Directives that guide the Engineering courses in Brazil and that define the principal questions for the construction of Pedagogic Projects for the Courses - PPPs. A theoretical and conceptual analysis will be carried out, since it is understood that only from this will we be able to understand what is expected from the engineer in terms of ability and competence, in addition to becoming essential elements in the construction of the Political Pedagogic Projects for the Courses in Engineering. "The Education of the Engineer from the perspective of STS: a reality to be studied", approaches questions relative to Science, Technology and Society - STS. The conceptions of STS have been the motive for constant studies among the diverse social segments. The purpose of this article is, therefore, to reflect on the possibility of educating citizen engineers that have the capacity to value academic knowledge in their day-to-day activities, interacting with the society of which they are a part.

Keywords: STS, engineering teaching, legislation in effect. .

\section{Introdução}

Inicialmente, neste artigo, serão apresentadas algumas concepções teóricas a fim de esclarecer alguns pontos de vista a respeito dos paradigmas educacionais e ensino de engenharia e da epistemologia da construção do conhecimento em educação e as concepções de CTS.

Em relação à Educação, considera-se como uma prática social, que ocorre em épocas históricas, constituída por ideologias particulares e cercado por subjetividades. Faz parte da Sociedade e está vinculada a seus objetivos e interligada a formação do cidadão que dela compartilha.

Quando se reflete sobre a Educação acredita-se que ela deva estar empenhada em ver o sujeito como um ser histórico, palpável e legítimo. Para isto ela deve basear-se num processo que abarque a observação ante os acontecimentos, as concepções, as interpretações e a ações diante dos eventos em si. Além disso, está inserida em seu contexto peculiar, conforme a visão de mundo, os valores e práticas sociais de uma cultura específica.

$\mathrm{Na}$ atualidade presenciam-se, muitas vezes perplexos, o contra-senso do desenvolvimento científico/tecnológico convivendo com intensas crises sociais. Em inúmeras ocasiões, devido a questões extremamente burocráticas, quando os modelos desvelam-se como insuficientes para 
responder aos aspectos da complexidade social, aparece uma sensação de desorientação e apatia frente às reflexões mais necessárias, abarcando todos os campos do fazer humano.

A Educação, ambiente de questionamentos, revela-se como um espaço indispensável para estas reflexões. Podemos verificar que em muitos níveis de ensino há uma inquietação a respeito da inabilidade de se estabelecer projetos que conduzam à emancipação e inclusão dos segmentos sociais frente à Ciência e a Tecnologia.

O desafio do Ensino Superior é, portanto, o de indicar ações de construção de alternativas. Para isto, é importante, a proposição de uma visão integralizadora e transdisciplinar de todos os envolvidos na elaboração de políticas educacionais. Makovieky (2001) afirma que transdisciplinar é a epistemologia da interdisciplinaridade, ou seja, é a área de conhecimento que se dedica a verificar como se dá o conhecimento de forma interdisciplinar, como se aprende a ser interdisciplinar. É a sistematização do conhecimento, a construção do conhecimento. A transdisciplinaridade é a filosofia, o pensamento que ajuda a construir a interdisciplinaridade.

Em decorrência desta mudança de postura, principalmente epistemológica, pode-se atuar mais efetivamente na construção de currículos e programas que conduzam a promoção de reflexões críticas, de investigações e de propostas para a solução dos problemas sociais vigentes. Isto contribuiria de maneira significativa e qualitativa para ações efetivas, visando à melhoria da qualidade de vida da população.

O incremento e ampliação desenvolvimentista de uma sociedade não se constituem linearmente. É fundamental a construção de um projeto onde ocorra a conscientização dos que a integram e mecanismos viáveis de mudanças práticas nesta sociedade. Este é o papel da Educação: construir e compartilhar deste projeto.

As ações educativas, ao longo da história, vão sendo modificadas, pois as concepções do ser humano também se transformam, interferindo diretamente na sua forma de agir e de pensar sobre as diversas problemáticas existentes no cotidiano social, político, cultural e ambiental.

A visão de mundo de cada um e do coletivo é constituída através da cultura acumulada na Sociedade, por meio das crenças compartilhadas, dos valores e das experiências, das referências históricas e culturais e dos estudos e pesquisas. O conjunto de visões de mundo forma a memória coletiva e constroem a identidade da própria Sociedade.

Existem múltiplas e variadas visões de mundo, segundo Norton (1991) o ser humano pode ser classificado, basicamente, em duas categorias quando o assunto é visão de mundo. Ele pode ter uma visão fragmentada e dissociada do mundo. Nesta perspectiva, o homem tende a reduzir as explicações à simplificação, a fazer previsibilidade, perdendo a essência e o significado e desta forma distorcendo a realidade. De acordo com essa visão esperam-se sempre as mesmas 
conseqüências para as mesmas causas. Perde-se a visão do todo, das relações e do conjunto. Esta postura tem servido, para muitos, para explicar o mundo até agora.

Já a visão integradora é interligada por diferentes fatores, tudo depende das relações e por isso nada é previsível ou determinista. É um sistema complexo, onde se buscam superar a ruptura e as limitações entre as práticas, os saberes e a vida. É composta por conhecimentos que foram acumulados a partir de experiência, de informações, de saberes e de modelos de pensamento que foram herdados e transmitidos pela tradição, pela Educação e pela comunicação social, sendo socialmente elaborado e compartilhado entre diferentes grupos.

Quando se aborda a concepção de Ciência, Tecnologia e Sociedade - CTS analisa-se através da visão de mundo integradora e dinâmica, pois esta permite lidar com a complexidade das relações entre os homens, em diferentes escalas espaciais e temporais, caracterizando uma postura epistemológica abrangente, que se fundamenta na construção e reconstrução permanente da própria visão e das concepções delas decorrentes.

CTS é uma construção coletiva que leva as marcas do tempo, do espaço e das relações que a constituem. É responsável pela articulação das diversas partes da totalidade científica, tecnológica e social na qual opera. É o resultado e a resultante da Educação, influenciando e recebendo influências da sociedade, da cultura e das características psicológicas individuais (conscientes e inconscientes) dos coletivos de pensamento com as quais se relaciona direta ou indiretamente.

A provocação, portanto, sobretudo para os que avaliam e se dedicam às ações educacionais, é a indicação de caminhos adequados para preparar, os cidadãos de diferentes segmentos para conviverem em espaços sociais plurais e que demandam conhecimentos, competências e atitudes constantemente atualizados e articulados em termos de teoria e prática.

A formação cidadã do profissional engenheiro aqui pretendida é uma meta que a cada dia se fortalece, pelo menos como aspecto teórico. É necessário traduzi-la em ações. De acordo com a nossa concepção, formação cidadã refere-se à inclusão dos acadêmicos nas problemáticas das comunidades e o estabelecimento por ele e por todos os envolvidos no processo de aprendizagem de pontes entre os conteúdos ministrados na sua graduação e as relações que pode constituir entre a sua profissionalização e a Sociedade. Isso minimiza as críticas de que muitos estudantes passam pela universidade sem terem contato prático com a realidade e não conseguem produzir conhecimentos capazes de sanar os problemas sociais mais emergentes.

O ensino universitário deve oferecer condições para que os alunos deixem de ser mais um e passem a ser sujeitos de sua própria história, sobretudo por meio da participação e do compromisso com a Sociedade. Desta maneira, a universidade transcende a função de mera formadora para o mercado de trabalho e faz com que os estudantes vivenciem intensamente 
todas as suas possibilidades e dimensões com vistas a uma formação integral, total e global. Oportunizam aos alunos a internalização de valores diversos entre eles os de democracia e justiça, fundamentais para sua participação na vida coletiva.

Bazzo (1998) defende um ensino que não aponte para uma formação estritamente técnica (formação do profissional), todavia que oportunize a reflexão das implicações políticas, econômicas, sociais e ambientais dos produtos destas áreas técnicas (Tecnologia). Segundo ele, há uma proposição de um estilo epistemológico por parte dos docentes, que conduziriam a uma reestruturação das práticas didático-pedagógicas, com o qual concordo.

A discussão sobre as transformações da sociedade atual passa, fundamentalmente, pelo colapso dos paradigmas antigos. São muitas as trajetórias para focalizar a crise, pois ela possui uma série de nuances. Isto também se reflete sobremaneira nas concepções de Ciência e Tecnologia.

É nesta conjuntura que debates a cerca de CTS têm auferido destaque, especialmente nas últimas décadas e vêm demarcando a construção de currículos de cursos superiores relacionados com as ciências em todo o planeta. (BRIDGSTOCK et al., 1998). Entre eles encontram-se os currículos de Medicina, Biologia, Engenharia, Ciências da Computação entre outros.

É importante destacar que se analisarmos a história, podemos verificar que após Segunda Guerra Mundial dois panoramas na universidade começaram a se distanciar: o das ciências e o das humanidades. As primeiras estavam em ascensão e "prometiam, com seus conhecimentos exatos e sua convertibilidade em Tecnologia útil na vida prática, sanar todos os problemas, eliminar a dor e o sofrimento, enfim, garantir progresso e conforto" (GOERGEN, 2000, p.153-4).

Este distanciamento conduziu a uma concepção de universidade com enfoque utilitarista, direcionada apenas às necessidades do mercado, a serviço do desenvolvimento econômico e tecnológico, com vistas a um modelo empresarial, e que ainda é percebida hoje, infelizmente, em alguns cursos que formam profissionais, como é o caso de algumas Engenharias.

"A estreita relação entre a Engenharia e os setores produtivos em destaque nos sistemas econômicos exerce uma acentuada pressão para a formação desses profissionais terem como base e referência as necessidades do mercado. Tendo em vista que essas necessidades aceleram-se, objetiva-se que a formação dos novos engenheiros ocorra em pouco tempo, enfatizando o imediatismo e a dimensão utilitária da formação profissional.". (TORRES 2002, p. 191) 
As Instituições de ensino superior voltadas para a formação de engenheiros, por vezes refletem e desenham às vezes de forma contundente a história, as composições de poder e a atmosfera política do grupo que as sustentam.

É notória a necessidade contemporânea de se refletir e agir acerca do ensino de Engenharia e principalmente sobre a formação dos Engenheiros. De acordo com Ferraz (1993) não se aventar à possibilidade única de apresentar ao ser humano ferramentas tecnológicas de poder, entretanto transformar essas ferramentas empoderando a sociedade, a fim de conduzir os sujeitos na busca de seus ideais de vida.

O campo específico da Ciência e da Tecnologia, assim como as áreas do ensino em Engenharia demonstram deficiências, o que torna necessário o empenho de todos os agentes envolvidos para transformar os paradigmas atuais em relação as perspectiva da Educação Científica e Tecnológica.

Especificamente os cursos de Engenharia deveriam priorizar uma formação científica, tecnológica e social com aprofundamento no desenvolvimento de ações que capacite os cidadãos para a constituição de novos esquemas, novos desenhos de comportamento ao invés de reproduzir modelos sociais e verdades inquestionáveis.

Segundo Colombo (2004) a epistemologia subjacente ao ensino de Engenharia é a empirista, desta maneira o conhecimento é entendido como algo que vem do mundo do objeto (meio físico ou social) tornando, muitas vezes, o educando passivo. Os cursos de Engenharia precisam ter a consciência, de sua posição de destaque, oportunizando ações transdisciplinares para além das discussões teóricas, como imperativo de vida.

A Engenharia ao longo de sua história sua atuação está ligada ao incremento cientifico e tecnológico, tanto no ponto de vista de seu ensino quanto de sua profissionalização. No instante em que a hegemonia da Ciência e da Tecnologia é discutida, em que as intromissões do ser humano na natureza vão desvendando seu sentido mais crucial, em que as disparidades sociais estão cada vez mais manifestas e injustas, em que os interesses econômicos individuais ou de pequenos grupos impõem-se aos da coletividade é necessário uma ação: a análise acerca da afinidade entre a Engenharia e os pleitos econômico-tecnológicos, sob alicerces ajustados a paradigmas socialmente inclusivos.

É necessário redefinir e redimensionar o papel da Engenharia nos projetos de modernidade, estabelecendo reflexões sobre a sua missão e as suas articulações com os demais segmentos.

As ações, em Engenharia, conectam-se inteiramente com a existência humana, da mesma maneira que dela dependem. Concordar com esta interdependência é comprometer-se como 
engenheiro e, principalmente como docente engenheiro na formação diferenciada dos novos profissionais. É interpretar o ambiente a fim de orientar, nortear e concretizar os planejamentos, os sonhos, os projetos que são solicitados pela coletividade. Essa ação está atrelada à cultura, a evolução do meio social e as oportunidades para sua efetivação.

Entende-se que a visão epistemológica, apresentada por todos os envolvidos que compõem uma instituição refletem significativamente as ações que esta produz, tendo por conseqüência modificações nas ações metodológicas. Assim a concepção de CTS que se fundamenta numa raiz epistemológica interiorizada individualmente e coletivamente reflete implícita ou explicitamente nos procedimentos didático-metodológicos das práticas educativas.

A formação acadêmica necessita oportunizar ao estudante a capacidade de reconhecer os problemas relevantes de seu entorno, avaliando distintas posições em relação a ele e de maneira consciente, atuar junto à sociedade.

O desenvolvimento de competências é apregoado pela LDB. Caracterizando a competente aquele que "constitui, articula, mobiliza valores, conhecimentos e habilidades para a resolução de problemas não só rotineiros, mas também inusitados em seu campo de atuação". Desta forma, competente é a pessoa que opera com eficácia diante do imprevisto, sobrepujando o conhecimento acumulado e atuando de forma transformadora e criativa.

Muitas são as ações que envolvem CTS, entre elas encontramos as que visam o desenvolvimento econômico e social. É importante ressaltar que muitas vezes acreditamos que uma mudança na metodologia de trabalho irá favorecer uma mudança de postura quanto a determinadas concepções. Nem sempre isso é verdadeiro. Por exemplo, podemos utilizar aulas com trabalhos em equipes, debates, seminários, mas para isso utilizarmos a base de conteúdos tradicionais. Ou ainda podermos ter um discurso completamente construtivista, e agirmos de forma tecnicista ou tradicional.

A concepção de CTS caracteriza-se como fundamentos primordiais para consecução dos pressupostos teóricos e metodológicos inerentes às práticas pedagógicas institucionais que podem promover alterações significativas ou reproduzir padrões sociais vigentes.

Nos cursos de Engenharia, as concepções positivistas da Ciência ainda estão presentes. Segundo Torres (2002, p. 52), a "finalidade desses cursos é a formação de profissionais que atendam às necessidades do desenvolvimento econômico e tecnológico".

A despeito de numerosos estudos serem desenvolvidos de maneira individual onde se percebe a preocupação com a trajetória dos cursos de Engenharia, muitas vezes existem apenas ações isoladas, que carecem de fundamentação teórico-crítica em relação à Ciência, à Tecnologia e a Sociedade. Isso provavelmente é decorrente da história desde a constituição da área002E 
O docente engenheiro necessita dos conhecimentos recentes das disciplinas que leciona, mas, além disso, carece também de conteúdos de ordem psicológica, sociológica, pedagógica e metodológica. É fundamental também uma cultura geral para estabelecer relações em nível filosófico-político a fim de compreender a função social da Engenharia.

A LDB busca garantir maior flexibilidade na organização dos cursos e carreiras, a fim de atender à crescente diversidade da formação precedente e às expectativas de todos os interessados neste nível de ensino.

As Diretrizes Curriculares propõem que os professores encarem o desafio do processo de modificação da ação pedagógica, a fim de que transforme o educando em um cidadão pleno. Nesta perspectiva, o enfoque CTS poderá ser encarado como uma maneira de conceber o conhecimento de forma integral, socialmente produzido, desenvolvendo um posicionamento acadêmico menos determinista e ideológico, priorizando a análise crítica e a produção do conhecimento em um sujeito competente para interferir de maneira consciente na Sociedade.

Para isso, é imprescindível analisar tanto as formas de pensar dos responsáveis pela elaboração dos PPPs dos Cursos de Engenharia, quanto em modelos teóricos que fundamentam os paradigmas ali presentes, já que os conceitos que possuímos são reflexos dos valores que cada momento histórico desenvolve e revela. Esses valores são demarcados pelos aspectos políticos, culturais e ambientais no contexto em que se está inserido.

Desta forma, sendo o PPP uma construção coletiva de todos os elementos que se somam na elaboração das políticas educativas a serem desenvolvidas por um determinado curso, acredita-se que ele retrate a visão de mundo deste coletivo, e expresse suas concepções epistemológicas e a relação destas com as práticas didático-pedagógicas desenvolvidas.

\section{Legislação nacional: um recorte para os cursos de engenharia}

\section{Implicações da LDB e das Diretrizes Curriculares para os cursos de Engenharia}

As Diretrizes e Bases para a Educação Nacional (LDB), corporificada na Lei 9.394 (1996), procura atualizar os sistemas educacionais para que os mesmos se adaptem aos novos desafios da contemporaneidade. Isto certamente conduzirá a mudanças de concepções filosóficas, sociológicas e pedagógicas bastante significativas para todo o processo educativo.

A LDB (1996) determina as finalidades essenciais da educação superior, no Brasil. Estas finalidades estão assim descritas: estimular a criação cultural, o desenvolvimento do espírito 
científico e do pensamento reflexivo; formar diplomados nas diferentes áreas de conhecimento, aptos para a inserção em setores profissionais e para a participação no desenvolvimento da sociedade brasileira, colaborando para uma formação contínua; desenvolvimento da ciência e da tecnologia e da criação e difusão da cultura e, desse modo, desenvolver o entendimento do homem e do meio em que vive; promover a divulgação de conhecimentos culturais, científicos e técnicos que constituem patrimônio da humanidade e comunicar o saber através do ensino, de publicações ou de outras formas de comunicação; suscitar o desejo permanente de aperfeiçoamento cultural e profissional e possibilitar a correspondente concretização, integrando os conhecimentos que vão sendo adquiridos numa estrutura intelectual sistematizadora do conhecimento de cada geração; estimular o conhecimento dos problemas do mundo presente, em particular os nacionais e regionais, prestar serviços especializados à comunidade e estabelecer com esta uma reação de reciprocidade; continuar a formação cultural e profissional dos cidadãos pela promoção de formas adequadas de extensão cultural.

Além das finalidades já expressas, a LDB (1996) também estabelece algumas prioridades para o ensino superior, dentre as quais se podem destacar: concentração de esforços para o resgate da qualidade do ensino na tentativa de favorecer melhores oportunidades aos alunos que forma, colaborando na sua profissionalização; desenvolvimento da crítica e a autocrítica do trabalho docente; formação de diplomados nas diferentes áreas do conhecimento, aptos para inserção em setores profissionais para a participação no desenvolvimento da sociedade brasileira.

Ao analisarmos, portanto, a LDB, observa-se a necessidade das universidades em desenvolverem projetos que abarquem três enfoques significativos: o da qualidade de ensino, o da análise da prática pedagógica dos docentes e o da formação acadêmica direcionada para o desenvolvimento científico, tecnológico estabelecendo uma interligação destes com as necessidades sociais.

Quanto às questões relativas à CTS, a Lei no. 9394/96, das Diretrizes e Bases da Educação Nacional, especificamente, em seu capítulo IV, artigo 43 apresenta menções explícitas e implícitas sobre o assunto, quando se refere aos princípios científicos e tecnológicos que presidem a produção moderna; o incentivo ao trabalho de pesquisa e investigação científica, visando ao desenvolvimento da ciência e da tecnologia; a determinação de uma educação profissional, integrada às diferentes formas de educação, ao trabalho, à ciência e à tecnologia.

Além da LDB, o Conselho Nacional de Educação e a Câmara de Educação Superior, segundo a resolução CNE/CES 11, de 11 de março de 2002 instituem Diretrizes Curriculares Nacionais do curso de graduação em Engenharia. Essas Diretrizes Curriculares devem ser observadas na organização curricular, através do desenvolvimento e avaliação de seus Projetos Pedagógicos, nas Instituições do Sistema de Educação Superior do Brasil. 
As Diretrizes Curriculares Nacionais (DCN, 2002) definem a identidade formativa, tanto relativa às questões humanas e como as profissionais. Além disso, deliberaram sobre as orientações pedagógicas, a matriz curricular e a estrutura acadêmica para o seu funcionamento.

"O caminho apontado pelas Diretrizes Curriculares Nacionais do curso de graduação em Engenharia para a definição do perfil profissional dos novos engenheiros mostra que os desafios são numerosos e exigem uma formação ao mesmo tempo técnica e humanística, além de um aprimoramento constante. No entanto, os currículos dos cursos de Engenharia sempre foram construidos numa lógica instrumental, tecnicista e que privilegiava a acumulação de conteúdos como garantia para a formação de um bom profissional" (DOMINGOS e FRANCINETE, 2006).

Se analisarmos as Diretrizes Curriculares para os Cursos de Engenharia (2002), pode-se destacar as seguintes competências e habilidades gerais para os alunos Engenheiros: aplicar conhecimentos matemáticos, científicos, tecnológicos e instrumentais à Engenharia; projetar e conduzir experimentos e interpretar resultados; conceber, projetar e analisar sistemas, produtos e processos; planejar, supervisionar, elaborar e coordenar projetos e serviços de Engenharia; identificar, formular e resolver problemas de Engenharia; desenvolver e/ou utilizar novas ferramentas e técnicas; supervisionar a operação e a manutenção de sistemas; avaliar criticamente a operação e a manutenção de sistemas; comunicar-se eficientemente nas formas escrita, oral e gráfica; atuar em equipes multidisciplinares; compreender e aplicar a ética e responsabilidade profissional; avaliar o impacto das atividades da Engenharia no contexto social e ambiental; avaliar a viabilidade econômica de Projetos de Engenharia; assumir a postura de permanente busca de atualização profissional.

Por conseguinte, os Engenheiros deverão possuir uma formação generalista, humanista, crítica e reflexiva. Devem ser capacitados para compreender as tecnologias atuais, bem como desenvolver novas tecnologias. Para isto, necessitam ser incentivados a desenvolverem uma atuação crítica e criativa na identificação e resolução de problemas. Estes aspectos deverão relacionar-se com as questões políticas, econômicas, sociais, ambientais e culturais, com visão ética e humanística para o atendimento das demandas da sociedade.

Em termos de legislação, temos ainda o parecer CNE/CES 1362/2001, que aborda a necessidade do ensino de Engenharia brasileiro formar profissionais de altíssima qualidade para o atendimento, em nível mundial das demandas oriundas da ciência e tecnologia.

Ciência e Tecnologia (C\&T) têm sido considerado um binômio, tratado no singular, em virtude da forte interação e interdependência entre ambas. Mais do que a própria evolução da Ciência foi a rapidez com que o conhecimento se transformou em uma invenção e este em uma 
inovação, disseminando o seu uso prático, que mudou de forma significativa à visão do homem de si mesmo e a sua forma de viver.

Quando se reflete acerca do próprio conceito de qualificação profissional observamos seu aprimoramento. "O conceito de qualificação profissional vem se alterando, com a presença cada vez maior de componentes associadas às capacidades de coordenar informações, interagir com pessoas, interpretar de maneira dinâmica a realidade. O novo engenheiro deve ser capaz de propor soluções que sejam não apenas tecnicamente corretas, ela deve ter a ambição de considerar os problemas em sua totalidade, em sua inserção numa cadeia de causas e efeitos de múltiplas dimensões." (DOMINGOS e FRANCINETE, 2006).

Desta forma, não basta para a formação do engenheiro apenas o conhecimento técnico e científico, embora muito importantes. Uma formação como esta está fadada a estagnação de seus profissionais. Exige-se deste novo profissional elementos associadas às competências de coordenar informações, interagir com outros sujeitos, decodificar de modo abrangente a realidade, indicando soluções para problemas específicos, bem como para analisar os problemas em sua totalidade. A habilidade de avaliação multidimensional e a análise de causa e efeito são fundamentais.

"Faz-se mister adotar uma postura arrojada frente às necessidades de formação técnica e humana do profissional do novo século. As escolas de formação devem assegurar ao acadêmico uma preparação mais adequada para que, ao iniciar sua vida profissional, o faça com segurança, preparo e maior capacidade criativa, contribuindo para a construção de uma nação onde o papel da cidadania seja mais respeitado por todos". (MORALES, 1997, p.31)

Como habilidades para que o profissional contemporâneo melhore sua atuação (técnica, social e humanística) é exigido que tenha capacidade de analisar e desenvolver novas técnicas, que interaja com a realidade e que se expresse corretamente tanto na escrita como verbalmente.

Entendo, concordando com Colombo $(2004,05)$ que o futuro profissional tem um "papel de ator e não de espectador, fazendo-o perceber-se como um sujeito que age a favor ou contra a qualidade de vida da coletividade, e não sujeitando a um mercado que incita necessidades nem sempre geradoras de melhor qualidade de vida; um sujeito capaz de escolher a orientação que dará à sua atuação".

A adaptação dos cursos de Engenharia às Diretrizes Curriculares demandará diversos estudos que fundamentem a opção acerca do perfil profissional que se aspira formar. Devem-se considerar as demandas sociais e do mercado bem como as suas tendências, para um levantamento dos conhecimentos exigidos na atualidade e no futuro para a atuação profissional. 
Nesta perspectiva, cada curso de Engenharia deve ter um Projeto Pedagógico que demonstre ampla e detalhadamente seus objetivos e como os conjuntos de atividades executados desenvolverão as características e competências esperadas para o profissional que está formando.

Projeto Político Pedagógico de Curso (PPPc) é um documento de referência do conjunto de ações e deliberações do curso. Todo PPPc, deve relacionar a especificidade da(s) área(s) de conhecimento(s) no contexto do respectivo processo histórico de determinado campo de saber. É premente que se constitua como um o espaço específico articulado à sua história.

Os componentes essenciais de Projeto Político Pedagógico são: fundamentos teóricometodológicos; concepção do curso/perfil do curso; objetivos/conteúdos; profissional que se deseja formar; concepção da organização curricular e avaliação do curso.

Os Projetos Políticos Pedagógicos devem ressaltar o imperativo de se abreviar o tempo em sala de aula, mudando este conceito de que o aluno só aprende no espaço físico da Universidade e na interação direta com o professor e seus alunos. É importante apropriar-se de outras concepções valorizando as atividades complementares, incentivando as ações acadêmicas individuais e entre os diferentes segmentos da Universidade. Ações entre os alunos de mesmo curso, de cursos afins, de cursos de áreas distintas, com sues professores, com outros professores de áreas correlatas ao curso e mesmo professores de áreas distintas, incentivando a discussão entre diversidades, a fim de enriquecer sua visão de mundo e sua formação acadêmica. Para isso, o incentivo às atividades como iniciação científica, ações de extensão, projetos multidisciplinares, visitas técnicas, trabalhos em equipe, desenvolvimento de protótipos e maquetes, monitorias, participação em empresas juniores e diferentes ações empreendedoras são exemplos desta mudança do conceito de sala de aula que não restringe a aprendizagem a "quatro paredes".

Para tanto, as IES (Instituições de Ensino Superior) devem considerar as suas especificidades e suas missões, partindo de estudos sobre as suas inserções em níveis local, regional e nacional, estando ao mesmo tempo, inseridas localmente e conectadas globalmente.

Perante aos desafios para a formação profissional estabelecido na legislação vigente é indispensável inserir na educação em Engenharia procedimentos pedagógicos atualizados, abalizados na aprendizagem, que propiciem o aprender a aprender e a empreender. Desta forma, habilitar os futuros profissionais para ultrapassarem os desafios de um mercado competidor e globalizados, para trabalharem com ambigüidade, para utilizar-se de múltiplas oportunidades de geração de renda e emprego, levando sempre em consideração as necessidades sociais mais prementes.

Uma ressalva quanto ao assunto precisa ser mencionada. De nada adianta termos valores apregoados na legislação se na prática não houver correspondência entre as determinações e sua 
efetivação. Há que se refletir acerca do papel dos educadores e estudantes no mundo atual, assinalado pelas transformações e pelas mudanças em múltiplos campos. Não basta reconhecêlas. É necessário que sejamos capazes de criar condições para intervir nessas transformações, no sentido em que, como atores principais da história, somos responsáveis, e muito, pela própria história que construímos. Acredito que apenas o requisito legal não avaliza o seu concreto desenvolvimento. Precisamos de ações que possam colocar em prática os ditames apregoados pela legislação.

\section{A formação do engenheiro numa perspectiva de cts}

No que se refere à Ciência e à Tecnologia observa-se que em diferentes níveis de ensino, historicamente tem-se adotado uma postura de valorização da concepção de neutralidade da ciência, além de colocar o cientista em um patamar mais elevado onde somente ele é o produtor de conhecimentos que irão beneficiar a população. Geralmente este tipo de abordagem não considera assuntos relacionados à época presente, não apreciando fatos do cotidiano e muitas vezes descomprometido com questões sociais.

De acordo com Bazzo (2002) a educação tecnológica, ministrada no domínio acadêmico e em particular nos cursos de Engenharia, está muito atrelada a enfoques eminentemente técnicos, que ignoram as influências mútuas entre a sociedade e o desenvolvimento científico e tecnológico.

No entanto, já temos estudos de algumas alternativas que estão interligados a abordagens educacionais mais progressistas. Estas proposições buscam discussão de propostas pedagógicas onde haja a construção de cidadãos embasados em princípios de justiça social que busquem a modificação da sociedade.

Torna-se necessário, portanto, uma análise do contexto acadêmico, ou seja, uma reflexão mais abrangente das finalidades da ação educativa, dos valores a serem construídos, do perfil do homem que se deseja alcançar, constituindo-se num exame criterioso e aprofundado dos componentes sócio-culturais que norteiam a filosofia dos cursos de Engenharia.

Atuando desta maneira, é possível que a formação do engenheiro também ajuste os seus objetivos às necessidades do homem e assim atenda as finalidades educativas expressas pela cultura social.

Quando se analisa o processo educativo atual verificam-se algumas contradições: a distância existente entre os conteúdos oferecidos pela Universidade e as demandas dos educandos; a não-interligação entre os conhecimentos aprendidos no ciclo básico e a sua 
aplicabilidade nas disciplinas profissionalizantes dos cursos de Engenharia; a direcionalidade dos conteúdos para aspectos muito complexos sem a elaboração prévia de conceitos e estruturas cognitivas; a fragmentação dos conteúdos sem que o aluno perceba a noção do todo e os níveis elevados de reprovação nas disciplinas.

Na modernidade, o ensino de Engenharia desenvolvido nas universidades causa, muita preocupação à comunidade e aos especialistas, pois sua validade e real importância para a sociedade moderna são muito questionadas.

Essa afirmação e corroborado por Bringhenti (1993, p. 116) quando menciona que "o ensino de Engenharia, até hoje, não se pautou por uma reflexão pedagógica sobre como se deveria ensinar Engenharia. A pedagogia empregada está inteiramente inadequada ao processo de aprendizagem".

Um dos imperativos básicos para mudança deste quadro é a compreensão de que o docente de Ciência e Tecnologia não é um mero "transmissor" de conhecimentos técnicos acabados. Por melhor que seja este ensino, o educador possui compromissos éticos e sociais que vão além do ensino da técnica. Não é mais possível desconsiderar que sua atuação educativa possua conseqüências. Ainda que indiretamente a ação docente perpassa valores sociais e culturais interferindo nas escolhas que realiza, tanto em termos de técnicas como em termos de concepções e posicionamentos e isto recai sobre um compromisso implícito que não pode ser ignorando ou negligenciando.A Engenharia deve preocupar-se com os problemas sociais de forma integrada nas suas dimensões ecológica, social, econômica, científico e tecnológico, com vista a promover um desenvolvimento equilibrado e sustentado.

É importante analisar, o papel da ciência e da tecnologia e a sua relação com os efeitos que produzem na sociedade. Tem-se que propor alternativas para revisão deste contexto, que de um lado é fascinante e de outro amedrontador. Por esse motivo, é necessário que se discuta, se analise e se avalie, a forma de produzir o conhecimento tecnocientífico com a qualidade e as conseqüências que essa forma de utilização, muitas vezes fragmentada e linear pode trazer para a sociedade.

\section{Conclusão}

É notória a premência contemporânea de se refletir e agir acerca do ensino de Engenharia, foco deste artigo, e principalmente sobre a formação dos Engenheiros. De acordo com Ferraz (1993) não se aventar à possibilidade única de apresentar ao ser humano ferramentas científicas e tecnológicas de poder, entretanto transformar essas ferramentas empoderando a sociedade, a fim de conduzir os sujeitos na busca de seus ideais de vida. 
Desta forma, torna-se necessário, uma reavaliação. Não há como sustentar a estrutura de alguns cursos superiores, caracterizados essencialmente pela fragmentação entre as disciplinas e a divisão dos saberes que geram e resguardam.

“É sob esses termos amplos que o ensino superior, em todos os lugares, está sendo chamado para tornar-se mais bem ajustado e responder melhor às demandas dos tempos nos quais novas oportunidades são acompanhadas por novos desafios e movimentos. Está claro que o ensino superior, como muitos outros níveis e formas de Educação, está sendo chamado a um reexame. O ensino superior está sendo solicitado a desenvolver, com todos os parceiros importantes, uma visão compreensiva de seus objetivos, tarefas e funcionamento". (DELORS 1999, p.23)

Elementos como currículo, aprendizagem, ensino e avaliação centrado no enfoque CTS de acordo com Waks (1993, pp.16-17), requerem "uma transferência da autoridade de professor e dos textos para os estudantes, individual e coletivamente; uma mudança na focalização das atividades de aprendizagem do estudante individual para um grupo de aprendizagem; uma mudança no papel dos professores como distribuidores de informações autorizadas, de uma autoridade posicional a uma autoridade experimental na situação da aprendizagem".

O ensino de Engenharia manifesta-se como uma ação educativa e sócio-cultural de valor imprescindível para o progresso de todas as atividades humanas, tanto individuais como coletivas. Desta forma, só se justifica e tem razão de existir quando estiver profundamente voltado para o aperfeiçoamento e promoção das capacidades humanas e sociais. Ele deve constituir-se em um processo analítico, crítico e dinâmico com vistas ao aperfeiçoamento das condições de satisfação sociais.

Torna-se necessário, desta forma, uma revisão sobre as metodologias de ensino e práticas pedagógicas desenvolvidas nos Cursos de Engenharia para a concretização destes objetivos. No entanto, mais importante que as mudanças metodológicas, em termos de currículos, o fundamental é uma transformação epistemológica. Portanto, os documentos que legislam sobre o ensino de Engenharia, merecem análise criteriosa para verificar as concepções que perpassam esta área de conhecimento.

Entendo que a visão epistemológica, apresentada por todos os envolvidos que compõem uma instituição refletem significativamente as ações que esta produz, tendo por conseqüência modificações nas ações metodológicas. Assim a concepção de CTS que se fundamenta numa raiz epistemológica interiorizada individualmente e coletivamente reflete implícita ou explicitamente nos procedimentos didático-metodológicos das práticas educativas.

Nesse contexto, é adequado refletir sobre as questões sociais relevantes, o progresso científico-tecnológico, entre outras. Além disso, é imprescindível analisar temas relacionados ao 
ensino de Engenharia, suas finalidades e princípios tanto em seus aspectos de desenvolvimento pessoal, quanto de desenvolvimento social e conhecimento científico-tecnológico.

Percebo, por exemplo, que é indispensável desenvolvermos reflexões sobre as concepções de toda a comunidade acadêmica a cerca da neutralidade da Ciência, da Tecnologia e das interações desta com a Sociedade; uma análise apropriada a respeito da tecnocracia e da formação de uma cultura de decisões participativas.

Colombo (2004, p. 150) faz um questionamento muito consistente a respeito deste assunto:

"Como é possivel formar Engenheiros criativos, sensiveis, humanos, cidadãos, se os professores (Engenheiros) são reprodutores, "quadrados", que "têm uma visão muito reduzida, muito racional, muito econômica", se eles são "muito práticos, muito objetivos". A mudança precisa começar, então, por eles, pela sua sensibilização, pela sua "humanização" e também pelo aprendizado e adoção de outros métodos de ensino-aprendizagem.".

É necessário, desta forma, perceber que existe intencionalidade em todas as ações, que esta se origina na estrutura epistemológica, e está interligada a uma série de crenças, valores, técnicas e interesses, e depende das escolhas realizadas, do destino que implementamos as realizações, bem como do paradigma adotado para que ações efetivas conduzam a mudanças à sociedade.

\section{Referências}

BAZZO, W. A. Ciência, tecnologia e sociedade: e o contexto da educação tecnológica. Florianópolis: Editora da UFSC, 1998.

BAZZO, W. A. A pertinência de abordagens CTS na educação tecnológica. Revista Iberoamericana de Educación - Número 28 Enseñanza de la tecnología / Ensino da tecnología. Enero-Abril 2002 / Janeiro-Abril 2002.

BRASIL. Ministério da Educação e do Desporto. Lei no 9.394 de 20 de dezembro de 1996. Lei de diretrizes e bases da educação nacional. Disponível em <www.mec.gov.br/sesu> Acesso em agosto de 2001.

BRIDGSTOCK, M. et al. Science, Technology and Society: An Introduction.Cambridge: University Press, 1998.

BRINGHETI, I. O ensino na Escola Politécnica da USP - Fundamentos para o ensino de engenharia. São Paulo: Ed. Universidade de São Paulo, 1993. 
COLOMBO, Ciliana Regina. Princípíos Teórico-Práticos para Formação de Engenheiros Civis: Em Perspectiva de uma Construção Civil Voltada ao Desenvolvimento Sustentável. Tese de Doutorado em Engenharia de Produção da Universidade Federal de Santa Catarina, Florianópolis $-2004$.

COLOMBO, Ciliana R., BAZZO, Walter. A. Educação tecnológica contextualizada, ferramenta essencial para o desenvolvimento social brasileiro. Biblioteca Virtual da OEI - Ciencia, tecnología y sociedad - Enseñanza técnica <http://www.campus-oei.org/oeiv >, 2001 e Revista de Ensino de Engenharia - ABENGE. Brasília, v. 20, nº1, p. 09-16, 2001.

CONSELHO NACIONAL DE EDUCAÇÃO. Câmara de Educação Superior. .Diretrizes Curriculares Nacionais dos Cursos de Engenharia. 2001.

DELORS, J. Educar para o futuro. O Correio da UNESCO, v. 24, n. 6, p. 6-11, jun.1996.

DIRETRIZES CURRICULARES PARA OS CURSOS DE ENGENHARIA. Projeto de Resolução. Brasília, 2002.

DOMINGOS, Fernanda de Castro. Biotecnologia e Engenharia Genética. FRANCINETE, Paulo Jr. A Engenharia, a Ciência e as Humanidades - Revista Humanidades em Foco.

www.cefetgo.brcienciashumanas/humanidades_foco/html/cienciaetecnologia_aeng. Acessoe em $23 / 05 / 2006$.

FERRAZ, H. A formação do engenheiro; um questionamento humanístico. São Paulo: Ática, 1983. GOERGEN, Pedro. Competências Docentes na Educação do Futuro. In CME-HISTEDBR. UnC. Caçador/ SC. v. 2 , n.1, 2000.

MAKOWIECKY, Sandra. Explicando o multidisciplinar, interdisciplinar e transdisciplinar. Universidade de Uberaba. Pró-Reitoria de Ensino de Graduação e extensão. <http://www.uniube.br/institucional/proreitoria/proes/programa.php>. Acesso em 23/02/2001. MORALES, Gilson. Proposta do Curso de Engenharia Civil da UNIVALI - Universidade do Vale do Itajaí. Londrina, abr. 1997.

NORTON,B.G. Ecological heath and sustentable resource management. New York: Columbia University, 1991.

TORRES, Suzana Rodrigues; A formação de docentes da engenharia e processos de mudanças: contribuições para a formação de professores. Tese (Doutorado em Psicologia da Educação) Pontifícia Universidade Católica de São Paulo (PUC), São Paulo - 2002.

WALKS, Leonard J. Value judgment and social action em technology studies. International Journal of Technology and Design Education. V.4, p. 35 - 49, 1994 
Tatiana C. Menestrina - Universidade do Estado de Santa Catarina - UDESC

tatiana@udesc.br

Walter Antônio Bazzo - Universidade Federal de Santa Catarina - UFSC

wbazzo@emc.ufsc.br 